\title{
AKSI PENCEGAHAN KASUS STUNTING DI KOTA SAMARINDA MELALUI PROGRAM PEMBANGUNAN DAN PEMBERDAYAAN MASYARAKAT (PRO-BEBAYA)
}

\section{(STUNTING CASE PREVENTION ACTION IN SAMARINDA CITY THROUGH COMMUNITY DEVELOPMENT AND EMPOWERMENT PROGRAM (PRO-BEBAYA))}

\author{
Fauziah $^{1}$, Dody Novandi ${ }^{2}$ \\ ${ }^{1}$ Akademi Kebidanan Bunga Husada Samarinda \\ Jalan Abdul Wahab Sjahranie Gang 3 Samarinda \\ Email: fauziah.fahrullah@gmail.com \\ ${ }^{2}$ Universitas Mulia Kampus Samarinda/Dinas Komunikasi dan Informatika Kota Samarinda \\ Jln. Pahlawan No. 2A Samarinda/Komplek Kantor Walikota Samarinda
}

Diterima: 22 September 2021; Direvisi: 8 Desember 2021; Disetujui: 30 Desember 2021

\begin{abstract}
This study aims to create a specific and sensitive nutrition intervention strategy by building the initiative and participation of the people of Samarinda City and agencies within the Samarinda City Government in overcoming stunting problems in Samarinda City. The data analysis method applied in this study is quantitative data analysis techniques to analyze the right strategy for stunting prevention in Samarinda City. The Community Development and Empowerment Program (PROBEBAYA) promoted by the Mayor of Samarinda and the Deputy Mayor of Samarinda at this time can be an instrument to be able to synergize various elements in supporting the implementation of specific and sensitive nutrition interventions for stunting prevention in Samarinda City. PROBEBAYA is able to become a new innovation and support the implementation of specific and sensitive nutrition interventions and can trigger the emergence of a structured, systematic and massive movement in reducing stunting prevalence in Samarinda City. In order to support the acceleration of stunting prevalence reduction in Samarinda City, the Samarinda City Government would be able to make PRO-BEBAYA a part of the stunting prevention action plan.
\end{abstract}

Keywords: Stunting, PRO-BEBAYA, Specific and sensitive nutrition interventions

\begin{abstract}
ABSTRAK
Penelitian ini bertujuan membuat strategi intervensi gizi spesifik dan sensitif dengan membangun prakarsa dan keikutsertaan masyarakat Kota Samarinda serta instansi di lingkungan Pemerintah Kota Samarinda dalam penanggulangan masalah stunting di Kota Samarinda. Metode analisis data yang diterapkan dalam penelitian ini yaitu teknik analisa data kuantitatif untuk menganalisa strategi yang tepat dalam rangka aksi pencegahan stunting di Kota Samarinda. Program Pembangunan dan Pemberdayaan Masyarakat (PRO-BEBAYA) yang diusung oleh Walikota Samarinda dan Wakil Walikota Samarinda pada saat ini bisa menjadi salah satu instrumen untuk bisa mensinergikan berbagai elemen dalam mendukung implementasi intervensi gizi spesifik dan sensitif untuk penanggulangan stunting di Kota Samarinda. PRO-BEBAYA mampu menjadi sebuah inovasi baru dan pendukung implementasi intervensi gizi spesifik dan sensitif serta bisa menjadi trigger munculnya gerakan secara terstruktur, sistematis dan masif dalam mereduksi prevalensi stunting di Kota Samarinda. Guna mendukung akselerasi penurunan prevalensi stunting di Kota Samarinda kiranya Pemerintah Kota Samarinda bisa menjadikan PRO-BEBAYA menjadi bagian dari rencana aksi pencegahan stunting.
\end{abstract}

Kata kunci: Stunting, PRO-BEBAYA, Intervensi Gizi Spesifik dan Sensitif 


\section{PENDAHULUAN}

Stunting merupakan sebuah kondisi dimana balita mengalami pertumbuhan yang tidak signifikan (pendek) yang biasa disebut dengan istilah kerdil yang dipicu ketiadaan gizi kronis karena rendahnya kuantitas dan kualitas gizi yang didapatkan dalam interval waktu yang lumayan lama (Laili \& Andriani, 2019). Stunting yang dialami oleh anak merupakan gambaran keadaan tidak suksesnya pertumbuhan pada anak dengan umur dibawah 5 tahun yang dipicu ketiadaan gizi akut, yang mengakibatkan seorang anak dengan kondisi terlalu pendek untuk umurnya pada saat itu. Kondisi ini terjadi dimulai bayi berada di dalam kandungan seorang ibu sampai dengan umur 2 tahun (Saputri, 2019).

Permasalahan stunting tidak hanya berdampak pada kesehatan seorang anak tetapi berdampak pada perkembangan trend produktivitas sumber daya manusia (SDM) pada sebuah daerah termasuk di Kota Samarinda. Seorang anak yang sehat, cerdas dan produktif merupakan aset penting karena merupakan generasi penerus dalam mendukung keberhasilan pembangunan di Kota Samarinda. Namun apabila anak-anak di Kota Samarinda lahir dan berkembang dalam kondisi kekurangan gizi akut, maka akan menyebabkan generasi penerus tersebut akan menjadi stunting.

Secara nasional pada tahun 2018 porsi bagian pada balita pada umur 0 sampai dengan 59 bulan yang menderita stunting dengan kategori sangat pendek sebesar $11,5 \%$ serta dengan kategori pendek sebesar 19,3\% (Indrayani, dkk, 2020). Trend keadaan ini mengalami peningkatan dari tahun yang sebelumnya dimana balita kategori sangat pendek adalah 9,8\% (Indrayani, dkk, 2020). Sedangkan kasus stunting pada balita pada umur 0 sampai dengan 23 bulan yang dengan kategori sangat pendek sebesar 12,8\% serta dengan kategori pendek sebesar 17,1\% (Indrayani, dkk, 2020). Trend keadaan ini mengalami peningkatan dari tahun yang sebelumnya dimana balita kategori sangat pendek adalah 6,9\% dan kategori pendek adalah 13,2\% (Indrayani, dkk, 2020).

Untuk lingkup provinsi Kalimantan Timur trend perkembangan kasus stunting dilihat dari data prevalensi stunting tahun 2016-2020 dapat dilihat pada Tabel 1.

Tabel. 1

Trend Perkembangan Data Prevalensi Stunting Propinsi Kalimatan Timur Tahun 2016-2020

\begin{tabular}{lccccc}
\hline \multirow{2}{*}{ Kabupaten/Kota } & \multicolumn{5}{c}{ Nilai Prevalensi (\%) } \\
\cline { 2 - 6 } & $\mathbf{2 0 1 6}$ & $\mathbf{2 0 1 7}$ & $\mathbf{2 0 1 8}$ & $\mathbf{2 0 1 9}$ & $\mathbf{2 0 2 0}$ \\
\hline Kabupaten Paser & 24,6 & 31,7 & 27,54 & 34,2 & 34,2 \\
Kabupaten Kutai Barat & 26,8 & 31,5 & 30,02 & 35,7 & 35,7 \\
Kabupaten Kutai Kertanegara & 37,1 & 30,9 & 35,66 & 36,5 & 36,5 \\
Kabupaten Kutai Timur & 29,8 & 32,4 & 30,45 & 39,3 & 39,3 \\
Kabupaten Berau & 27,2 & 30,4 & 31,6 & 24,6 & 24,6 \\
Kabupaten PPU & 27,1 & 32,4 & 31.62 & 27 & 27 \\
Kabupaten Mahakam Ulu & 30,8 & 30,5 & 32,84 & 36,5 & 36,5 \\
Kota Balikpapan & 24,3 & 30,2 & 23,77 & 14 & 14 \\
Kota Samarinda & 24 & 28,8 & 26,26 & 24,7 & 24,7 \\
Kota Bontang & 20,4 & 32,4 & 26,62 & 29 & 29 \\
\hline Suyyyyy
\end{tabular}

Sumber : Diolah dari berbagai sumber data

Pada tahun 2020 di Kota Samarinda kasus stunting yang dialami oleh balita sebanyak 1.402 balita yang terdiri dari balita dengan kategori sangat pendek sebanyak 403 balita dan kategori pendek sebanyak 999 balita (Dinas Kesehatan Kota Samarinda, 2021). Potret sebaran data stunting dapat dilihat pada display data pada Tabel 2, Tabel 3 dan Gambar 1. 
Aksi Pencegahan Kasus Stunting di Kota Samarinda Melalui Program Pembangunan dan Pemberdayaan Masyarakat (Pro-Bebaya)

\section{Fauziah, Dody Novandi}

Tabel 2.

Tabel Sebaran Balita dengan Kategori Sangat Pendek dan Pendek Per Kecamatan di Kota Samarinda Tahun 2020

\begin{tabular}{|c|l|c|c|}
\hline No & Kecamatan & $\begin{array}{c}\text { Balita } \\
\text { dengan } \\
\text { status } \\
\text { "Sangat } \\
\text { Pendek" }\end{array}$ & $\begin{array}{c}\text { Balita } \\
\text { dengan } \\
\text { status } \\
\text { "Pendek" }\end{array}$ \\
\hline 1 & Loa Janan Ilir & 52 & 125 \\
\hline 2 & Palaran & 94 & 279 \\
\hline 3 & Samarinda Ilir & 31 & 39 \\
\hline 4 & Samarinda Kota & 19 & 36 \\
\hline 5 & Samarinda Seberang & 20 & 53 \\
\hline 6 & Samarinda Ulu & 63 & 124 \\
\hline 8 & Samarinda Utara & 13 & 34 \\
\hline 9 & Sambutan & 3 & 9 \\
\hline 10 & Sei Kunjang & 77 & 254 \\
\hline
\end{tabular}

Sumber : Laporan Stunting (Dinas Kesehatan, 2021)

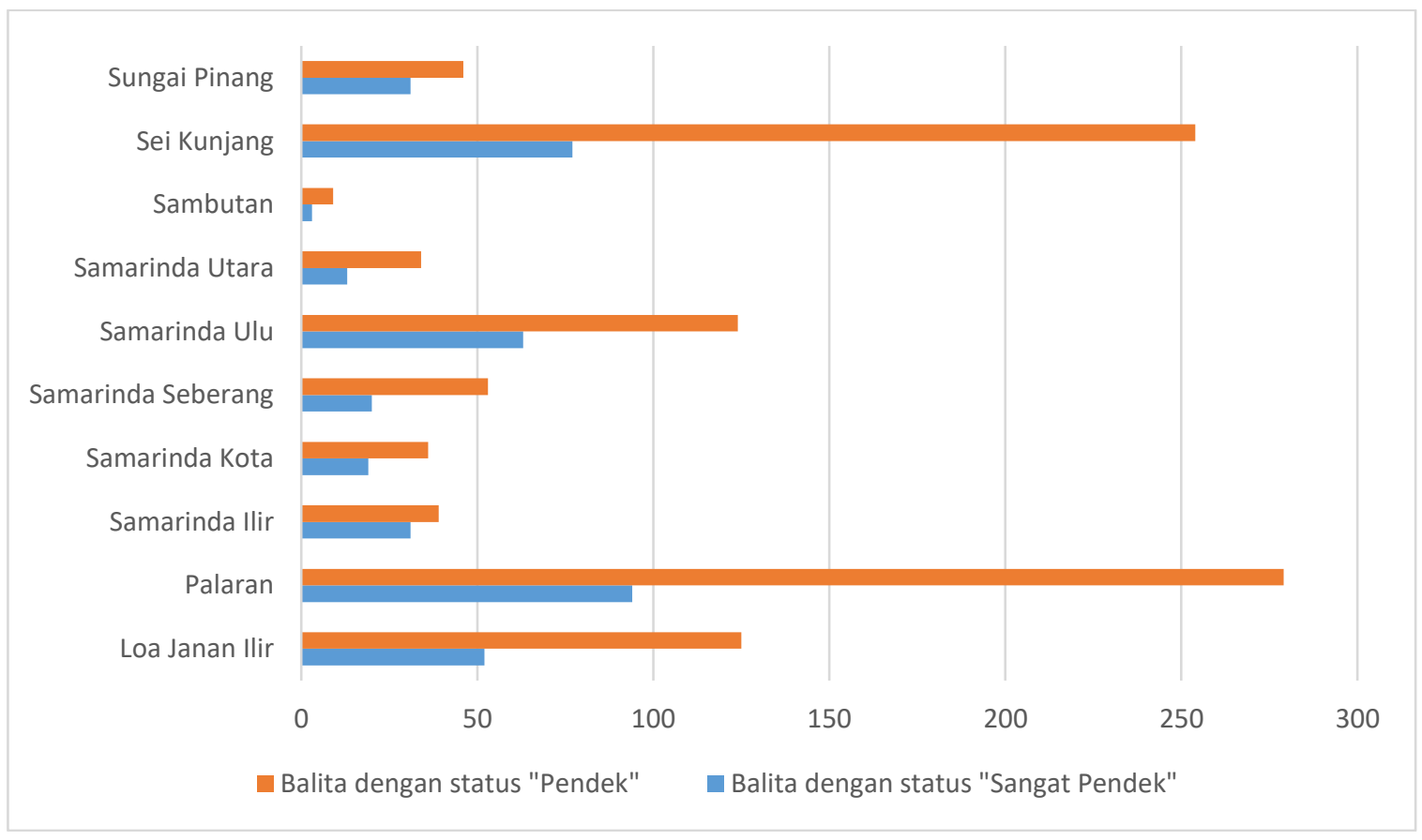

Gambar 1.

Grafik Sebaran Balita dengan Kategori Sangat Pendek dan Pendek Per Kecamatan di Kota Samarinda Tahun 2020

Sumber : Diolah (2021) 
Aksi Pencegahan Kasus Stunting di Kota Samarinda Melalui Program Pembangunan dan Pemberdayaan

Fauziah, Dody Novandi

Tabel 3.

Sebaran Balita dengan Kategori Sangat Pendek dan Pendek Per Kelurahan dan Puskesmas di Kota Samarinda Tahun 2020

\begin{tabular}{|c|c|c|c|c|c|c|}
\hline No. & Kecamatan & Puskesmas & Kelurahan & $\begin{array}{c}\text { Balita } \\
\text { dengan } \\
\text { status } \\
\text { "Sangat } \\
\text { Pendek" } \\
\end{array}$ & $\begin{array}{c}\text { Balita } \\
\text { dengan } \\
\text { status } \\
\text { "Pendek" }\end{array}$ & Total \\
\hline 1 & Loa Janan Ilir & Harapan Baru & Rapak Dalam & 0 & 0 & 0 \\
\hline 2 & Loa Janan Ilir & Trauma Center & Sengkotek & 20 & 44 & 64 \\
\hline 3 & Loa Janan Ilir & Trauma Center & Tani Aman & 19 & 38 & 57 \\
\hline 4 & Loa Janan Ilir & Trauma Center & Simpang Tiga & 8 & 36 & 44 \\
\hline 5 & Loa Janan Ilir & Harapan Baru & Harapan Baru & 5 & 7 & 12 \\
\hline 6 & Palaran & Bukuan & Bukuan & 39 & 134 & 173 \\
\hline 7 & Palaran & Palaran & Handil Bakti & 20 & 44 & 64 \\
\hline 8 & Palaran & Palaran & Simpang Pasir & 18 & 32 & 50 \\
\hline 9 & Palaran & Palaran & Rawa Makmur & 17 & 57 & 74 \\
\hline 10 & Palaran & Bantuas & Bantuas & 0 & 12 & 12 \\
\hline 11 & Samarinda Ilir & Sidomulyo & Selili & 19 & 23 & 42 \\
\hline 12 & Samarinda Ilir & Sidomulyo & Pelita & 0 & 1 & 1 \\
\hline 13 & Samarinda Ilir & Sidomulyo & Sungai Dama & 8 & 14 & 22 \\
\hline 14 & Samarinda Ilir & Sidomulyo & Sidomulyo & 4 & 1 & 5 \\
\hline 15 & Samarinda Ilir & Sidomulyo & Sidodamai & 0 & 0 & 0 \\
\hline 16 & Samarinda Kota & Samarinda Kota & Pelabuhan & 5 & 12 & 17 \\
\hline 17 & Samarinda Kota & Samarinda Kota & Sungai Pinang Luar & 8 & 12 & 20 \\
\hline 18 & Samarinda Kota & Samarinda Kota & Pasar Pagi & 5 & 0 & 5 \\
\hline 19 & Samarinda Kota & Samarinda Kota & Bugis & 1 & 6 & 7 \\
\hline 20 & Samarinda Kota & Samarinda Kota & Karang Mumus & 0 & 6 & 6 \\
\hline 21 & Samarinda Seberang & Mangkupalas & Mesjid & 10 & 24 & 34 \\
\hline 22 & Samarinda Seberang & Baqa & Baqa & 3 & 10 & 13 \\
\hline 23 & Samarinda Seberang & Mangkupalas & Tenun Samarinda & 0 & 1 & 1 \\
\hline 24 & Samarinda Seberang & Mangkupalas & Mangkupalas & 7 & 13 & 20 \\
\hline 25 & Samarinda Seberang & Baqa & S.Keledang & 0 & 5 & 5 \\
\hline 26 & Samarinda Seberang & Baqa & Gunung Panjang & 0 & 0 & 0 \\
\hline 27 & Samarinda Ulu & Juanda & Gn.Kelua & 22 & 20 & 42 \\
\hline 28 & Samarinda Ulu & Air Putih & Bukit Pinang & 22 & 18 & 40 \\
\hline 29 & Samarinda Ulu & Juanda & Air Hitam & 12 & 21 & 33 \\
\hline 30 & Samarinda Ulu & Segiri & Dadimulya & 0 & 17 & 17 \\
\hline 31 & Samarinda Ulu & Segiri & Sidodadi & 2 & 13 & 15 \\
\hline 32 & Samarinda Ulu & Air Putih & Air Putih & 5 & 4 & 9 \\
\hline 33 & Samarinda Ulu & Pasundan & Teluk Lerong Ilir & 0 & 16 & 16 \\
\hline 34 & Samarinda Ulu & Pasundan & Jawa & 0 & 15 & 15 \\
\hline 35 & Samarinda Utara & Sempaja & Sempaja Barat & 0 & 2 & 2 \\
\hline
\end{tabular}




\begin{tabular}{|c|c|c|c|c|c|c|}
\hline No. & Kecamatan & Puskesmas & Kelurahan & $\begin{array}{c}\text { Balita } \\
\text { dengan } \\
\text { status } \\
\text { "Sangat } \\
\text { Pendek" }\end{array}$ & $\begin{array}{c}\text { Balita } \\
\text { dengan } \\
\text { status } \\
\text { "Pendek" }\end{array}$ & Total \\
\hline 36 & Samarinda Utara & Lempake & Lempake & 0 & 3 & 3 \\
\hline 37 & Samarinda Utara & Sempaja & Sempaja Selatan & 1 & 4 & 5 \\
\hline 38 & Samarinda Utara & Bengkuring & Sempaja Timur & 11 & 4 & 15 \\
\hline 39 & Samarinda Utara & Sei Siring & Sei Siring & 0 & 13 & 13 \\
\hline 40 & Samarinda Utara & Bengkuring & Sempaja Utara & 1 & 1 & 2 \\
\hline 41 & Samarinda Utara & Sei Siring & Tanah Merah & 0 & 6 & 6 \\
\hline 42 & Samarinda Utara & Sei Siring & Budaya Pampang & 0 & 1 & 1 \\
\hline 43 & Sambutan & Makroman & Pulau Atas & 0 & 1 & 1 \\
\hline 44 & Sambutan & Sambutan & Sambutan & 1 & 3 & 4 \\
\hline 45 & Sambutan & Makroman & Makroman & 0 & 1 & 1 \\
\hline 46 & Sambutan & Sungai Kapih & Sungai Kapih & 2 & 4 & 6 \\
\hline 47 & Sambutan & Makroman & Sindang Sari & 0 & 0 & 0 \\
\hline 48 & Sei Kunjang & Loa Bakung & Loa Buah & 8 & 16 & 24 \\
\hline 49 & Sei Kunjang & Wonorejo & Kr Anyar & 11 & 102 & 113 \\
\hline 50 & Sei Kunjang & Wonorejo & Telok Lerong Ulu & 23 & 64 & 87 \\
\hline 51 & Sei Kunjang & Karang Asam & Karang Asam Ulu & 5 & 30 & 35 \\
\hline 52 & Sei Kunjang & Lok Bahu & Lok Bahu & 15 & 20 & 35 \\
\hline 53 & Sei Kunjang & Loa Bakung & Loa Bakung & 7 & 13 & 20 \\
\hline 54 & Sei Kunjang & Karang Asam & Karang As am Ilir & 8 & 9 & 17 \\
\hline 55 & Sungai Pinang & Remaja & Temindung Permai & 21 & 21 & 42 \\
\hline 56 & Sungai Pinang & Temindung & Sungai Pinang Dalan & 0 & 4 & 4 \\
\hline 57 & Sungai Pinang & Remaja & Gunung Lingai & 7 & 14 & 21 \\
\hline 58 & Sungai Pinang & Temindung & Mugirejo & 3 & 3 & 6 \\
\hline 59 & Sungai Pinang & Remaja & Bandara & 0 & 4 & 4 \\
\hline
\end{tabular}

Sumber : Laporan Stunting (Dinas Kesehatan, 2021)

Ada beberapa hal yang menjadi pemicu stunting antara lain yaitu: asupan yang diterima oleh ibu hamil sampai dengan setelah proses persalinan sangat sedikit, minimnya jangkauan ke fasilitas kesehatan, minimnya jangkuan air bersih serta sanitasi (Laili \& Andriani, 2019). Selain faktor secara langsung terjadinya stunting yang sudah dijelaskan sebelumnya, ada juga pemicu terjadinya stunting secara tidak langsung antara lain yaitu: penghasilan dan ketimpangan ekonomi, perdagangan, pergerakan komunitas dari pedesaan menuju perkotaan, globalisasi, metode ketahanan pangan, perlindungan sosial, sistem kesehatan, pengembangan pertanian, dan pemberdayaan wanita (Dirjen Bangda Kemendagri, 2020). 


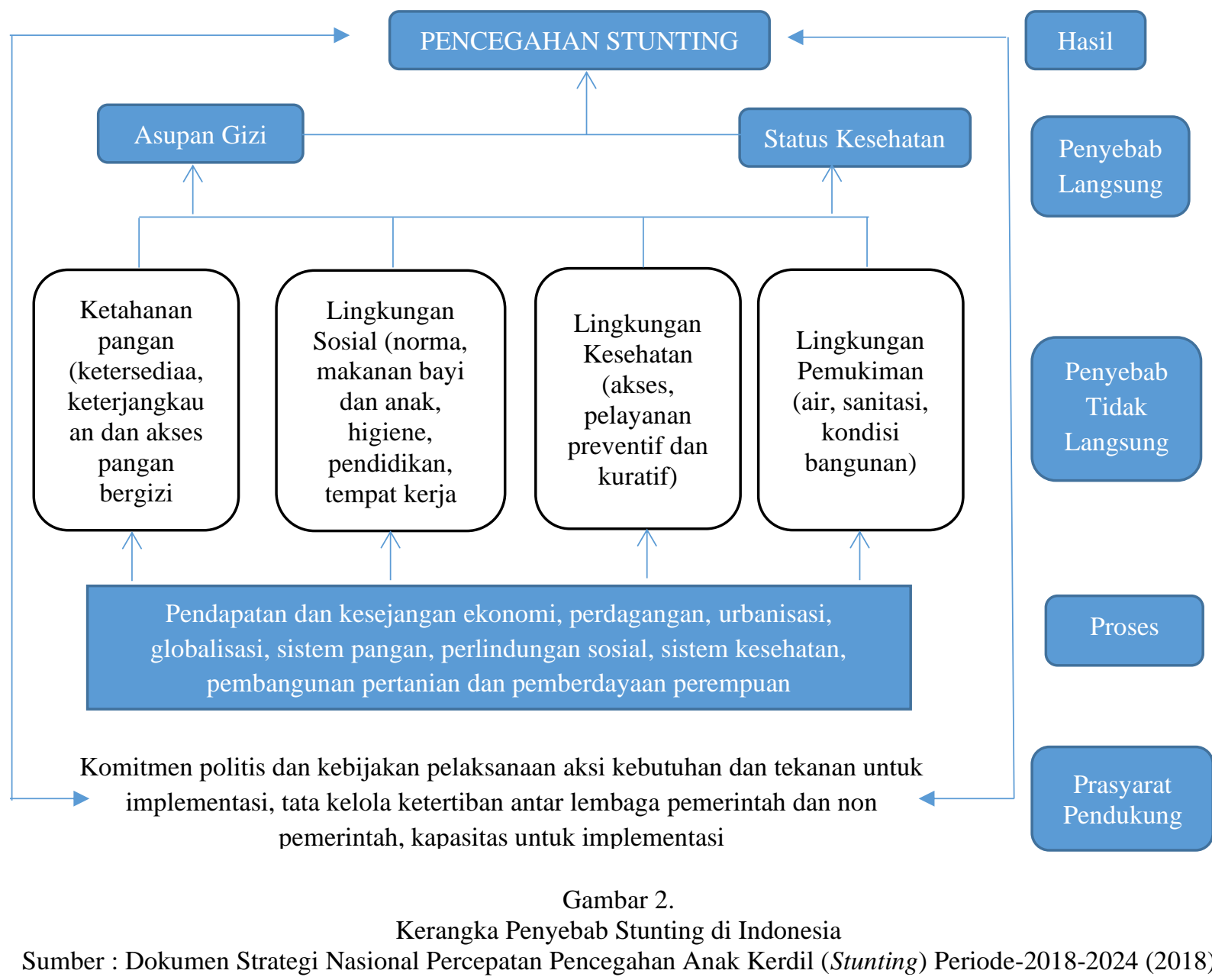

Menurut TNP2K (2017) dalam Saputri (2019), stunting bisa memperlambat laju kemajuan ekonomi dan mengurangi daya produksi kinerja pasar, sehingga menyebabkan terjadinya penurunan sebesar 11\% GDP (Gross Domestic Products) serta mereduksi penghasilan pekerja dewasa sampai dengan $20 \%$. Stunting juga bisa berpartisipasi terhadap meluasnya ketimpangan sampai dengan $10 \%$ terhadap kuantitas penghasilan seumur hidup serta dapat mengakibatkan kemiskinan antar keturunan.

Untuk mengatasi problematika kasus stunting di Indonesia, baru-baru saja Presiden Republik Indonesia Bapak Ir. Joko Widodo menetapkan Kepala BKKBN Hasto Wardoyo sebagai Ketua Pelaksana Percepatan Penurunan Stunting. Bapak Presiden Republik Indonesia menetapkan sasaran penurunan angka stunting Indonesia harus mampu turun 14\% sampai dengan tahun 2024 (Putri, 2021). Dengan sasaran yang telah ditetapkan, kasus stunting merupakan sebuah salah satu permasalahan secara nasional yang mendapat perhatian besar dalam penanggulangannya.

Berikut ini berbagai aksi pencegahan kasus stunting di berbagai daerah: 1) melakukan kombinasi strategi agresif berupa optimalisasi intervensi gizi spesifik dan sensitive (strategi jangka pendek), diintensifkan peluang dukungan kolaborasi antar sektor dan multistakehoders guna menjamin keberlanjutan dan pencapaian sasaran akselerasi penurunan stunting (strategi jangka panjang) di Desa Banyumundu, Kecamatan Kaduhejo, Kabupaten Pandeglang (Priyono, 2020). 2) peningkatan kapasitas kader posyandu berupa pelatihan memahami mengenai gizi seimbang, deteksi dini stunting dan peran penting kader posyandu menginformasikan gizi optimal pada 1000 HPK sebagai upaya pencegahan stunting serta mengidentifikasi faktor risiko 
penyebab stunting di wilayah kerja posyandu di Desa Cipacing Kecamatan Jatinangor Kabupaten Sumedang (Megawati \& Wiramihardja, 2019). 3) Peningkatan Pengetahuan Masyarakat Tentang Stunting Di Desa Slarang Kecamatan Kesugihan Kabupaten Cilacap (Kusumawati, Yunadi, Septiyaningsih, \& Budiarti, 2021). 4) Pemberian Makanan Tambahan (PMT) pada Balita dan Ibu Hamil, Pemberian Tablet Tambah Darah (TTD) pada remaja putri dan ibu hamiL, peningkatan cakupan imunisasi dasar lengkap pada bayi dan balita, pemberian vitamin A pada balita, dan pemberian zinc pada kasus diare terutama pada ibu hamil dan balita di Kabupaten Bangka dan Kabupaten Bangka Barat di Provinsi Kepulauan Bangka Belitung (Saputri, 2019). 5). Pendampingan kelas ibu hamil di Posyandu Sidomulyo, Kota Samarinda (Fauziah, Rahmawati, Imaroh, \& Yulianti, 2020)

Aksi pencegahan kasus stunting membutuhkan kolaborasi multi sektor serta mengikut sertakan berbagai elemen yaitu: Pemerintah Kota Samarinda, masyarakat dan lain-lain. Menurut Saputri (2019), Pemerintah Indonesia telah membuat desain intervensi penanganan stunting yang dibagi menjadi 2 (dua) bagian adalah : Intervensi Gizi Spesifik dan Intervensi Gizi Sensitif.

Saat ini Pemerintah Kota Samarinda sudah telah mempunyai Walikota dan Wakil Walikota yang baru, dimana ada beberapa program unggulan kepala daerah yang merupakan tindak lanjut atas visi misi Kepala Daerah Kota Samarinda. Adapun salah satu program unggulan tersebut adalah "Program Pembangunan dan Pemberdayaan Masyarakat (PRO-BEBAYA)",

PRO-BEBAYA merupakan sebuah program yang subtansinya adalah dinamika gotongroyong masyarakat sehingga dapat membawa dan menanggulangi setiap permasalahan dan guna mendukung akselerasi kegiatan pembangunan serta pengembangan tingkat derajat kesejahteraan masyarakat berdasarkan kewilayahan atau RT di Kota Samarinda (MAF, 2021). Program ini ditujukan guna mendukung proses pembentukan wirausaha baru paling sedikit berjumlah 2 sampai dengan 3 orang tiap lingkungan RT. Entititas targetnya yaitu bagi warga yang kurang mampu, aktivitas kebersihan lingkungan, dan lain-lain dalam bidang ekonomi, agama, sosial budaya, serta lingkungan hidup (MAF, 2021). Melihat esensi dari tujuan kegiatan PRO-BEBAYA, program ini sangat cocok dikolaborasikan terhadap strategi intervensi gizi spesifik dan sensitif dalam upaya pencegahan stunting di Kota Samarinda.

Berdasarkan potret sebaran stunting di Kota Samarinda pada tahun 2020 serta penjelasan permasalahan diatas tersebut, maka tim peneliti terdorong untuk membuat sebuah sebuah jurnal penelitian yang berjudul "Aksi Pencegahan Kasus Stunting di Kota Samarinda Melalui Program Pembangunan dan Pemberdayaan Masyarakat (PRO-BEBAYA)". Penelitian ini bertujuan membuat strategi intervensi gizi spesifik dan sensitif dengan membangun prakarsa dan keikutsertaan masyarakat Kota Samarinda serta instansi di lingkungan Pemerintah Kota Samarinda dalam penanggulangan masalah stunting di Kota Samarinda.

\section{TINJAUAN PUSTAKA \\ Stunting}

Menurut Rahmadhita (2020), stunting merupakan kondisi gizi yang berbasis pada indikator $\mathrm{PB} / \mathrm{U}$ atau $\mathrm{TB} / \mathrm{U}$ dengan mengunakan standar antropometri evaluasi kondisi gizi anak, perolehan pengukuran tersebut berkedudukan pada internal nilai yang dapat diterima (Z-Score) <-2 SD sampai batas -3 SD (pendek/stunted) dan <-3 SD (sangatpendek/severely stunted). Dengan merujuk ambang batas maka status stunting dapat dibedakan menjadi 2 kategori yaitu: pendek dan sangat pendek (Rahmadhita, 2020).

Beberapa indikator antropometri yang selalu dipakai menurut Kementrian Kesehatan RI (2017) dalam Rahmadhita (2020) yaitu berat badan berdasarkan usia bayi (BB/U), tinggi badan berdasarkan usia (TB/U), berat badan berdasarkan tinggi badan (BB/TB) yang ditetapkan menggunakan standar deviasi unit z (Z-score). 
Dalam sebuah modul yang dibuat oleh BKKBN RI bekerjasama dengan Yayasan Plan Internasional Indonesia yang berjudul "Modul Bina Keluarga Balita Eliminasi Masalah Anak Stunting (BKB-EMAS)", menyebutkan bahwa kegiatan intervensi preventif kasus stunting sangat ditentukan pada rentang waktu 1.000 HPK atau bisa dikenal dengan sebutan Hari Pertama Kehidupan saat seorang ibu mulai mengandung sampai seorang anak yang dilahirkan tersebut berusia 2 tahun. Waktu 1000 HPK adalah sebuah durasi bagi seorang anak terdiri dari 9 (sembilan) bulan selama dalam kandungan seorang ibu hamil dan 24 (dua puluh empat) bulan dari waktu kelahiran anak sampai dengan umur 2 tahun (BKKBN, 2018).

\section{Intervensi Gizi Spesifik}

Intervensi gizi spesifik yang diarahkan pada penyebab stunting yaitu: 1) kuantitas asupan makanan dan gizi yang baik; 2) Pemberian makanan, perawatan dan pola asuh; serta 3) Pengobatan infeksi/penyakit (Dokumen Strategi Nasional Percepatan Pencegahan Anak Kerdil (Stunting) Periode-2018-2024, 2018).

\section{Intervensi Gizi Sensitif}

Sasaran dari intervensi gizi sensitif yaitu keluarga serta masyarakat pada umumnya. Beberapa kegiatan yang dilakukan untuk intervensi gizi sensitif yaitu: (a) Pengembangan akses pangan bergizi; (b) Eskalasi tingkat kesadaran, komitmen dan praktik pengasuhan gizi ibu dan anak; (c) Pengembangan akses dan kualitas pelayanan gizi dan kesehatan; dan (d) Peningkatan penyediaan air bersih dan sarana sanitasi (Dokumen Strategi Nasional Percepatan Pencegahan Anak Kerdil (Stunting) Periode-2018-2024, 2018).

\section{Program Pembangunan dan Pemberdayaan Masyarakat (PRO-BEBAYA)}

Program Pembangunan dan Pemberdayaan Masyarakat (PRO-BEBAYA) merupakan sebuah kegiatan yang bertujuan menstimulasi akselerasi kegiatan pembangunan dan eskalasi kesejahteraan warga di Kota Samarinda. Dengan berkonsentasi terhadap RT, program ini diharapkan disparitas antar wilayah dan antar komunitas warga di Kota Samarinda tidak terjadi (Tim Kreatif Salam Perubahan, 2021).

PRO-BEBAYA merupakan cerminan progran yang terdapat pada dokumen Rencana Pembangunan Jangka Menengah Nasional 2020-2024 pada Misi Ketiga yaitu mewujudkan "PEMBANGUNAN YANG MERATA dan BERKEADILAN" dan diperjelas dalam kegiatan pembangunan nasional pada angka 2 yang tertulis "MENGEMBANGKAN WILAYAH UNTUK MENGURANGI KESENJANGAN dan MENJAMIN PEMERATAAN" (Tim Kreatif Salam Perubahan, 2021). PRO-BEBAYA mampu berkontribusi sebagai "hulu dan hilir" terhadap semua hasil kebijakan pemerintah kota serta menjadi garda terdepan untuk pelayanan publik (Tim Kreatif Salam Perubahan, 2021).

\section{METODE}

Jenis data yang digunakan dalam penelitian ini merupakan data sekunder yang bersumber dari Dinas Kesehatan Kota Samarinda berupa data stunting di Kota Samarinda di tahun 2020. Pengambilan data yang digunakan dalam penelitian ini dilakukan pada bulan Juli 2021. Data sekunder merupakan sumber data yang digunakan dalam sebuah penelitian dimana seorang peneliti mendapatkannya secara tidak langsung melalui medium penghubung (Syafnidawaty, 2021).

Teknik analisis data merupakan sebuah langkah untuk memproses data menjadi informasi. Saat kegiatan penelitian dilaksanakan seorang peneliti harus melakukan analisis data dengan tujuan agar data yang diperoleh mudah dipahami. Metode analisis data yang diterapkan dalam 
penelitian ini yaitu teknik analisa data kuantitatif dengan Systematic literature review menggunakan CASP ( Critical Appraisal Skill Programme) Checklist case study dengan membandingkan data dari Dinas Kesehatan Kota Samarinda dengan dokumen strategi nasional pencegahan stunting untuk menganalisa strategi yang tepat dalam rangka aksi pencegahan stunting di Kota Samarinda.

\section{HASIL DAN PEMBAHASAN}

Penanggulangan pencegahan stunting di Kota Samarinda tidak akan maksimal apabila hanya dilaksanakan oleh satu individual saja, dibutuhkan sinergi antara Pemerintah Kota Samarinda dengan masyarakat. Diperlukan komitmen bersama agar usaha akselerasi penurunan nilai prevalensi stunting bisa merata pada seluruh wilayah kelurahan di Kota Samarinda.

Dalam memaksimalkan penanganan stunting di Kota Samarinda, ada strategi yang bisa dilaksanakan yaitu dengan melakukan intervensi gizi spesifik dan sensitif. Intervensi gizi spesifik lebih mengarah kepada perbaikan stunting secara langsung dan intervensi gizi spesifik untuk perbaikan stunting secara tidak langsung.

Program Pembangunan dan Pemberdayaan Masyarakat (PRO-BEBAYA) yang diusung oleh Walikota Samarinda dan Wakil Walikota Samarinda pada saat ini bisa menjadi salah satu instrumen untuk bisa mensinergikan berbagai elemen dalam mendukung implementasi intervensi gizi spesifik dan sensitif untuk penanggulangan stunting di Kota Samarinda. Dengan melihat esensi dari PRO-BEBAYA sangat memungkinkan program ini mendukung penanganan salah satu permasalahan di Kota Samarinda untuk sektor kesehatan. Kegiatan PRO-BEBAYA serta intervensi gizi spesifik dan sensitif merupakan kolaboratif ideal untuk bisa menumbuhkan pemahaman masyarakat dan transisi karakter publik di Kota Samarinda guna melakukan preventif terhadap stunting.

\section{Strategi Intervensi Gizi Spesifik}

Salah satu tujuan yang ingin dihasilkan dalam pelaksanaan intervensi gizi spesifik yaitu pemberian kuantitas asupan makanan dan gizi yang baik. Derajat kesejahteraanmasyarakat dapat menjadi salah satu yang mempengaruhi pemberian asupan gizi kepada balita.Rendahnya pendapatan yang dihasilkan oleh masyarakat mengakibatkan kurangnya daya beli sehingga tidak mampu memenuhi konsumsi gizi yang ideal kepada balita.

Salah satu target dari Program Pembangunan dan Pemberdayaan Masyarakat (PRO-BEBAYA) adalah membentuk wirausaha baru di setiap lingkungan RT di Kota Samarinda. Untuk mengoptimalkan pencapaian tujuan dari strategi intervensi gizi spesifik ini maka salah satu target warga yang akan dijadikan calon wirausaha tersebut adalah warga dengan status tidak mampu dan memiliki anak berumur dengan interval 0 sampai dengan 23 bulan.

Sebagai upaya kesinambungan strategi ini, calon wirausaha yang telah berhasil dalam karyanya melalui PRO-BEBAYA diwajibkan mengajak beberapa warga lainnya yang tidak mampu serta memiliki anak berusia dengan interval 0-23 bulan disekitarnya untuk menjadi bagian dari kegiatan usahanya dengan tujuan untuk mendorong pertumbuhan derajat kesejahteraan masyarakat sehingga daya beli masyarakat menjadi stabil sehingga secara otomatis beberapa warga tersebut mampu memberikan konsumsi gizi yang ideal bagi balitanya. Mekanisme ini terus berlanjut dimana warga yang telah berhasil dari proses pengrekrutan oleh warga sebelumnya harus mengajak warga lainnya dengan kriteria yang telah ditetapkan.

\section{Strategi Intervensi Gizi Sensitif}

Dengan melihat subtansi dan karakteristik dari Program Pembangunan dan Pemberdayaan Masyarakat (PRO-BEBAYA), maka secara tidak langsung agenda dari PRO-BEBAYA ini 
merupakan manifestasi dari sasaran intervensi gizi sensitif. Hal ini terbukti dimana beberapa sasaran dari PRO-BEBAYA menyasar pada aktivitas kebersihan lingkungan, agama, dan sosial budayadi Kota Samarinda.

Masuknya aktivitas kebersihan lingkungan hidup di dalam PRO-BEBAYA dapat menjadi pendukung untuk mengatasi salah satu penyebab stunting yaitu lingkungan kesehatan dan permukiman. Selain itu juga kegiatan lain dalam bidang agama, sosial budaya yang termasuk pada PRO-BEBAYA bisa mendukung mengatasi salah satu penyebab stunting lainnya yang berkaitan dengan lingkungan sosial.

Ada sebuah kegiatan yang bisa direncanakan berkaitan guna mendukung intervensi gizi ini yaitu pelaksana kegiatan PRO-BEBAYA bekerjasama dengan beberapa elemen yaitu posyandu yang berada disekitar lingkungan RT, puskesmas dan Dinas Pengendalian Penduduk dan Keluarga Berencana Kota Samarinda untuk melakukakan kegiatan edukasi tentang pola asuh yang baik kepada ibu hamil, ibu menyusui yang memiliki anak dengan rentang umur 0 sampai 6 bulan, dan warga yang memiliki anak dengan umur 7 sampai dengan 23 bulan. Kegiatan ini bertujuan untuk menumbuhkan tingkat kesadaran dan pemahaman kepada orang tua sehingga kegiatan proses pengasuhan terhadap tumbuh kembang bisa dilakukan dengan baik dan benar untuk anak.

Sebagai wujud dukungan terhadap kegiatan intervensi gizi sensitif penyelenggara PRO-BEBAYA memasukan posyandu menjadi bagian dari sasaran dari program tersebut dengan harapan PRO-BEBAYA dapat melakukan penguatan kepada posyandu sebagai upaya pengembangan akses dan kualitas pelayanan gizi dan kesehatan di lingkungan RT. Posyandu mempunyai kapasitas yang signifikan guna mendeteksi secara dini apabila adanya praduga tanda-tanda seorang anak menuju ke gejala stunting. Posyandu yang berada di setiap lingkungan RT bisa menjadi elemen pertama dan kunci yang mampu menjangkau secara langsung guna melakukan pengawasan kesehatan dan tumbuh kembang balita di Kota Samarinda.

\section{KESIMPULAN}

Berdasarkan hasil dan pembahasan, maka tim penulis mengambil beberapa kesimpulan yaitu sebagai berikut :

1. Program Pembangunan dan Pemberdayaan Masyarakat (PRO-BEBAYA) mampu menjadi sebuah inovasi baru dan pendukung implementasi intervensi gizi spesifik dan sensitif dalam penanganan stunting di Kota Samarinda.

2. PRO-BEBAYA bisa menjadi trigger munculnya gerakan secara terstruktur, sistematis dan masif dalam mereduksi prevalensi stunting di Kota Samarinda.

Guna mendukung akselerasi penurunan prevalensi stunting di Kota Samarinda tim penulis menyarankan agar kiranya Pemerintah Kota Samarinda menjadikan PRO-BEBAYA menjadi bagian dari rencana aksi pencegahan stunting.

\section{UCAPAN TERIMAKASIH}

Kami selaku tim penulis mengucapkan terima kasih kepada beberapa pihak yang sudah mendukung dalam penyusunan artikel penelitian ini, yaitu:

1. Kepala Dinas Kesehatan Kota Samarinda

2. Kepala Kantor Universitas Mulia Kampus Samarinda

\section{DAFTAR PUSTAKA}

BKKBN RI, \& Yayasan Plan Internasional Indonesia. (2018). Modul Bina Kelaurga Balita Eliminasi Masalah Stunting (BKB-EMAS). Jakarta: BKKBN RI. 
Dinas Kesehatan, (2021). Data Prevalensi Stunting Provinsi Kaltim Tahun 2018-2020 https://data.kaltimprov.go.id/dataset/data-prevalensi-stunting-provinsi-kaltim-tahun2018-2020, diakses tanggal 9 Juli 2021

Direktorat Gizi Masyarakat, \& Direktorat Jenderal Kesehatan Masyarakat Indrayani. (2017). Hasil Pemantauan Status Gizi (PSG) dan Penjelasannya Tahun 2016. Jakarta: Kementerian Kesehatan RI

Fauziah, F., Rahmawati, R., Imaroh, U., \& Yulianti, Y. (2020). Upaya Meningkatkan Kesehatan Ibu Hamil Dan Janinnya Dengan Pendampingan Kelas Ibu Hamil Di Puskesmas Sidomulyo Samarinda. JURNAL ABDIMAS KESEHATAN PERINTIS , 812.

Indrayani, Y. A., \& dkk. (2020). Profil Kesehatan Indonesia Tahun 2019. Jakarta: Kementerian Kesehatan RI.

Kementerian Koordinator Bidang PMK, \& Sekretariat Wakil Presiden RI. (2021). Stranas Percepatan Pencegahan Anak Kerdil 2018-2024. Retrieved from Dokumen Penting: https://tp-pkk.rokanhulukab.go.id/web-

content/uploads/stranas_percepatan_pencegahan_anak_kerdil_2018_2024.pdf, diakses pada tanggal 15 Juli 2021

Kusumawati, D. D., Yunadi, F. D., Septiyaningsih, R., \& Budiarti, T. (2021). Peningkatan Pengetahuan Masyarakat Tentang Stunting Di Desa Slarang Kecamatan Kesugihan Kabupaten Cilacap. Jurnal Pengabdian Masyarakat Al-Irsyad (JPMA).

Laili, U., \& Andriani, R. A. (2019). Pemberdayaan Masyarakat Dalam Pencegahan Stunting. Jurnal Pengabdian Masyarakat Ipteks, 8-12.

MAF. (2021). Launching Pro Bebaya, Wali Kota Umumkan Kenaikan Insentif RT Jadi Rp1.000.000. Retrieved from PPID: https://ppid.samarindakota.go.id/berita/kabarpemerintahan/launching-pro-bebaya-wali-kota-umumkan-kenaikan-insentif-rt-jadirp1000000, diakses pada tanggal 17 Juli 2021

MAF. (2021). Siang ini Launching Probebaya, Target Ciptakan Minimal 3 Wirausaha Baru Tiap RT. Retrieved from PPID: https://ppid.samarindakota.go.id/berita/kabarpemerintahan/siang-ini-launching-probebaya-target-ciptakan-minimal-3-wirausahabaru-tiap-rt, diakses pada tanggal 17 Juli 2021

Megawati, G., \& Wiramihardja, S. (2019). Peningkatan Kapasitas kader Posyandu Dalam Mendeteksi dan Mencegah Stunting. Dharmakarya: Jurnal Aplikasi Ipteks untuk Masyarakat , 155-159.

Priyono, P. (2020). Strategi Percepatan Penurunan Stunting Perdesaan (Studi Kasus Pendampingan Aksi Cegah Stunting di Desa Banyumundu, Kabupaten Pandeglang). Jurnal Good Governance.

Putri, T. H. (2021). Jokowi Tunjuk Kepala BKKBN Jadi Ketua Pelaksana Penurunan Stunting . https://www.idntimes.com/news/indonesia/teatrika/jokowi-tunjuk-kepala-bkkbn-jadiketua-pelaksana-penurunan-stunting/3, diakses pada tanggal 18 Juli 2021

Rahmadhita, K. (2020). Permasalahan Stunting dan Pencegahannya. Jurnal Ilmiah Kesehatan Sandi Husada, 225-229.

Saputri, R. A. (2019). Upaya Pemerintah Daerah Dalam Penanggulangan Stunting di Provinsi Kepulauan Bangka Belitung. JDP (Jurnal Dinamika Pemerintahan), 152-168.

Syafnidawaty. (2020). Data Sekunder. https://raharja.ac.id/2020/11/08/data-sekunder/, diakses tanggal 17 Juli 2021.

Tasman, R., dkk. (2020). Analisis Kluster Kejadian Stunting pada Balita di Provinsi Kalimantan Timur. Jurnal Kesehatan, 8(3),143-150

Tim Kreatif Salam Perubahan. (2020). 10 Program Unggulan. Retrieved from https://kotaperadaban.com/\#visi, diakses pada tanggal 20 Juli 2021 